\title{
Playing the Sprint Retrospective
}

\author{
Maciej Wawryk \\ Gdansk University of Technology, Faculty of \\ Electronics, Telecommunications and Informatics \\ Narutowicza 11/12, 80-233 Gdansk, Poland. \\ Email:wawryk2@gmail.com
}

\author{
Yen Ying $\mathrm{Ng}$ \\ Gdansk University of Technology, Faculty of \\ Electronics, Telecommunications and Informatics \\ Narutowicza 11/12, 80-233 Gdansk, Poland. \\ Department of English Studies, Nicolaus Copernicus \\ University, Torun, Poland. \\ Email: nyysang@gmail.com
}

\begin{abstract}
In this paper, we report on a replication of the study by Przybylek \& Kotecka [2017]. The aim of our study was to revise the work practices related to Sprint Retrospectives in Bluebay Polska Sp. z.o.o. by adopting collaborative games. The feedback received from two Scrum teams confirms the findings from the original study and indicates that collaborative games improve participants' creativity, involvement, and communication as well as produce better results than the standard retrospective.
\end{abstract}

\section{INTRODUCTION}

A GILE methods appeared as a reaction to traditional ways of developing software and acknowledged that customers are unable to definitively state their needs up front [Przybyłek, 2014; Przybyłek \& Zakrzewski, 2018]. In agile software development requirements and solutions evolve through the collaboration of all stakeholders. The Agile Manifesto [Highsmith \& Fowler, 2001] advocates principles and values such as face-to-face conversation within a development team, motivated individuals, self-organizing teams, and retrospectives at regular intervals. Furthermore, agile team members are expected to be proactive and creative in resolving complex software development problems [Highsmith \& Cockburn, 2001; Crawford et al., 2012; Przybyłek \& Zakrzewski, 2018; Przybyłek \& Kowalski, 2018; Jarzębowicz \& Ślesiński, 2018; Miler \& Gaida, 2019; Zakrzewski et al., 2019]. However, agile methods do not provide techniques to promote these attitudes. Responding to this challenge, Przybyłek and his team [Przybyłek \& Olszewski, 2016; Przybyłek \& Kotecka, 2017; Przybyłek \& Zakrzewski, 2018; Przybyłek \& Kowalski, 2018; Zakrzewski et al., 2019] proposed to equip agile teams with collaborative games.

Collaborative games refer to structured techniques inspired by game play, but designed for the purpose of solving practical problems [Przybyłek \& Kotecka, 2017], for example they are quite widely used as a requirements elicitation technique [Marciniak \& Jarzębowicz 2016, Przybyłek \& Zakrzewski, 2018]. By involving visual activities like moving sticky notes and drawing pictures, they leverage multiple dimensions of communication, which results in deeper, richer and more meaningful exchanges of information [Przybyłek \& Kowalski, 2018; Hohmann, 2006]. Besides, various studies suggest that fun is a powerful tool in unleashing creativity and facilitating collaboration [Hohmann, 2006; Trujillo et al., 2014; Ghanbari et al., 2015].

Przybyłek \& Kotecka [2017] demonstrated that the promised benefits of collaborative games were materialized when running a game-based retrospective in 3 teams in Intel. The Sprint Retrospective is a meeting in which the team inspects and adapts its way of working [Ilyés, 2019]. Its purpose is to recognize the successes and failures of the last Sprint and to link the related experience to action proposals for improvements. In this paper, we report on a replication of the study conducted in Intel [Przybyłek \& Kotecka, 2017]. The feedback received from 2 Scrum teams confirms the findings from the original study and indicates that collaborative games improve participants' creativity, motivation, communication, knowledge sharing, make participants more willing to attend Scrum meetings, and produce better results than the standard retrospective.

The remainder of this paper is organized as follows. Section II provides an overview of the previous studies. Section III explains the employed research methodology. Section IV reports the research project and its results. Finally, the last section concludes the paper.

\section{RELATED WORK}

Recently, there has been lots of interest in adopting collaborative games to aid agile teams. Przybyłek \& Olszewski [2016] defined an extension to Open Kanban, which consists of 12 collaborative games broken down into four categories in accordance with four Open Kanban principles. The extension was proved to assist unskilled team members better understand the principles of Kanban and promote the teamwork.

Przybyłek \& Zakrzewski [2018] proposed a framework for extending Scrum with 9 collaborative games. The framework was proved to boost agile requirements engineering. 
Przybyłek \& Kowalski [2018] developed a web portal which provides 8 collaborative games to be used in agile software development.

Przybyłek \& Kotecka [2017] adopted 5 collaborative games to support running an effective and enjoyable retrospective meetings. Our study is a continuation of their work, since we evaluate these games in other company and teams.

\section{RESEARCH METHOD}

Our study was conducted as Action Research [Baskerville \& Myers, 2004]. In Action Research, the researcher works in close collaboration with a group of practitioners, acting as a facilitator, to solve a real-world problem while simultaneously expanding scientific knowledge [Przybyłek \& Zakrzewski, 2018]. The researcher brings his knowledge of action research while the practitioners bring their practical knowledge and context [Baskerville \& Myers, 2004]. A precondition for Action Research is to have a problem owner willing to collaborate to identify a problem, engage in an effort to solve it, analyze the results, and determine future actions [Przybyłek \& Zakrzewski, 2018]. The problem owner in this research was Bluebay Polska Sp. z.o.o.. The company was interested in auditing its work practices related to Sprint Retrospectives and improving identified deficiencies. Two Scrum teams participated in the study (Table I). Team 1 developed a web store for Aclari Diamonds, which is a jewellery company, while Team 2 developed print management software for POSperita, which is a printer $\&$ advertising agency.

TABLE I.

PARTICIPATING TEAMS (ROLE, EXPERIENCE IN YEARS)

\begin{tabular}{|l|l|}
\hline \multicolumn{1}{|c|}{ Team 1 } & \multicolumn{1}{c|}{ Team 2 } \\
\hline $\begin{array}{l}\text { Team Leader \& Scrum Master, } \\
\text { 10 }\end{array}$ & $\begin{array}{l}\text { Team Leader \& Scrum Master, } \\
10\end{array}$ \\
\hline Developer, 5 & Developer, 8 \\
\hline Developer, 3 & Developer, 6 \\
\hline Tester, 2 & Developer, 5 \\
\hline & Tester, 5 \\
\hline
\end{tabular}

\section{ACTION RESEARCH IN BLUEBAY POLSKA}

We identified that our teams encountered similar problems related to Sprint Retrospective as those presented in the original study [Przybylek \& Kotecka, 2017]. Accordingly, we decided to implement all the games except $\mathrm{Mad} / \mathrm{Sad} / \mathrm{Glad}$, which was depreciated in the original study and revised by Mood++. In addition, we decided to try one new game, i.e. $360^{\circ}$ Appreciation.

$360^{\circ}$ Appreciation [Caroli \& Caetano, 2016] is a game to foster a conducive working environment that strengthens people relationship and increases team morale. It allows open positive feedback within a team as well as appreciating the time and energy spent by the team members. In other words, it focuses only on the developers' strength instead of their weaknesses, which can be rather discouraging. The game is not complicated as it can be conducted in any environment. What is more, no additional equipments such as blackboards, posters and sticky notes are required. To run this activity, the facilitator asks everyone to write down their appreciations about one another on a piece of paper. After that, the team is asked to form a circle with one participant sitting in the middle. The other participants are asked to read their appreciation feedback to the one in the center. The same process is repeated until everybody in the team has received feedback.

Each game was implemented twice in each team. Before a game was run for the first time, it was presented to the team. After each game session, we issued a questionnaire to collect feedback from the participants. The responses were made on a five-point Likert scale. Finally, the results were analyzed and discussed with the participants.

All games except 5L's and $360^{\circ}$ appreciation were evaluated positively with respect to all categories. Playing 5L's consumed too much time, while the obtained results were worse when compared to Starfish, Sailboat or Mood++. As for $360^{\circ}$ appreciation, even though it got low scores for questions 3-6, it is still successful overall, because it was not designed to promote these issues. The game was considered helpful in relieving the tension or getting to know new team members. Since this game does not provide any feedback on the issues during the Sprint, it should be combined with other collaborative game when performed during the retrospective. In turn, Sailboat was especially appreciated for allowing participants to identify risks in a project. The detail results are presented in Fig. 1.

\section{CONCLUSIONS}

This paper reports on an Action Research project in conducted in Bluebay Polska Sp. z.o.o. Following the best practices developed by Przybyłek \& Kotecka [2017], we revitalized retrospectives by adopting collaborative games. The feedback gathered from two Scrum teams confirms the previous findings that game-based retrospectives produce better results than standard retrospectives and lead to a variety of measurable societal outcomes. In particular, Starfish, Sailboat, and Mood++ improved participants' creativity, motivation, communication, knowledge sharing and make participants more willing to attend Scrum meetings.

As future work, we want to measure in a quantitative experiment with settings similar to [Przybyłek, 2018] whether game-based retrospectives are more effective than standard retrospectives. Moreover, after collecting more data, we plan to build a recommender system [Karpus, 2019] that will help scrum teams to choose a retrospective game suitable for a given context. 
1. The game produces better results than the standard approach

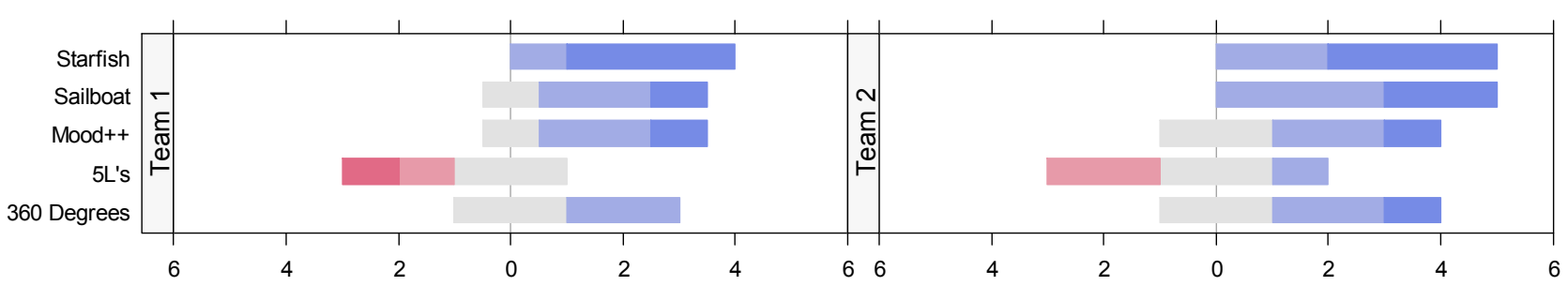

2. The game should be permanently adopted by your team

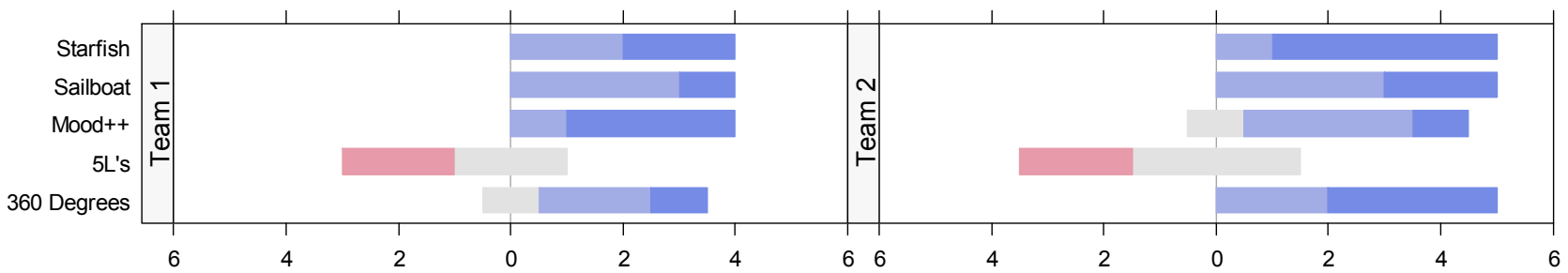

3. The game fosters participants' creativity

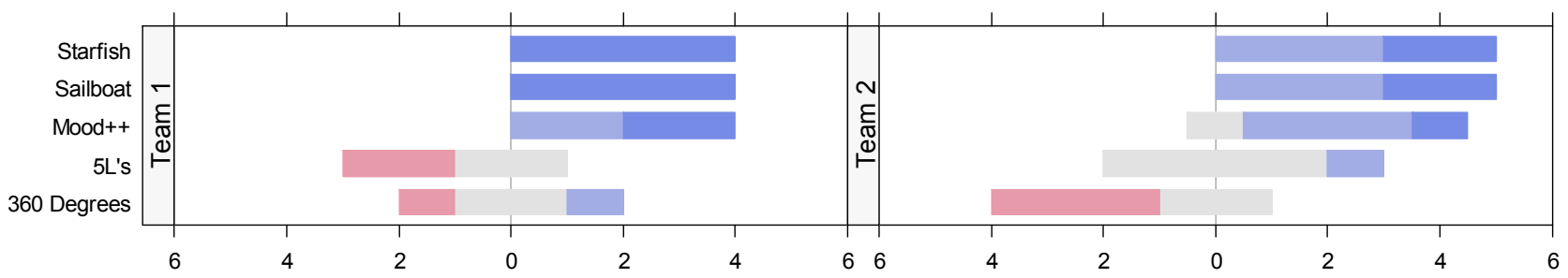

4. The game fosters participants' motivation and involvement

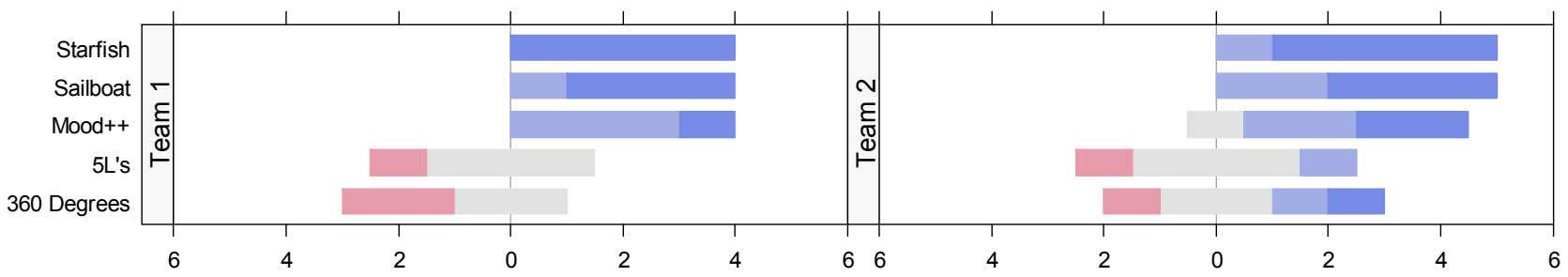

5. The game improves communication among the team members

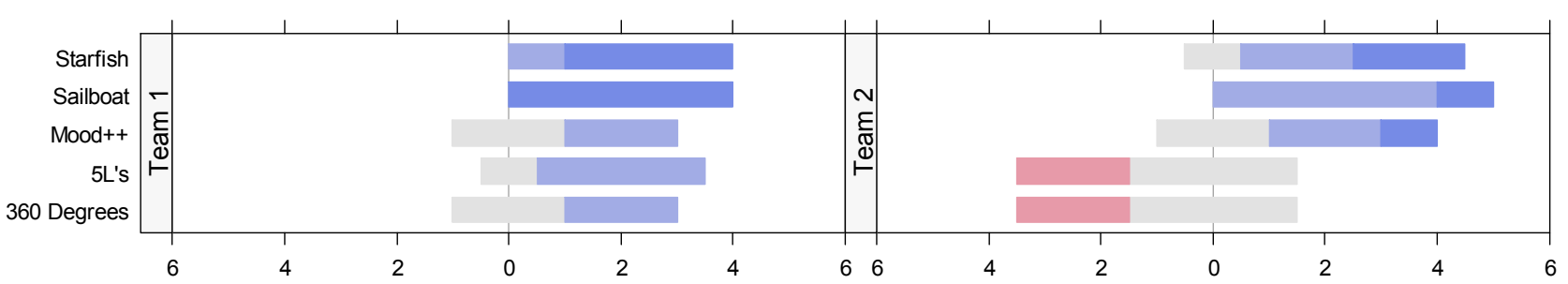

6. The game facilitates knowledge sharing among the participants

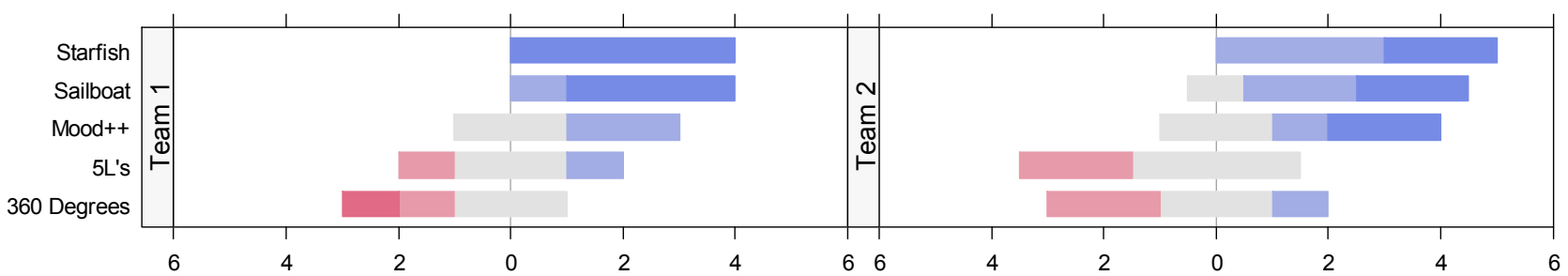




\section{The game makes participants more willing to attend the meeting}

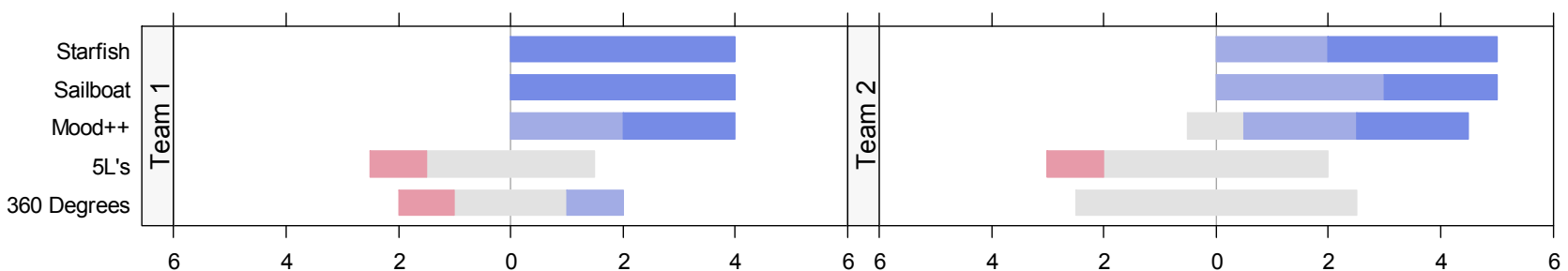

8. The game is easy to understand and play

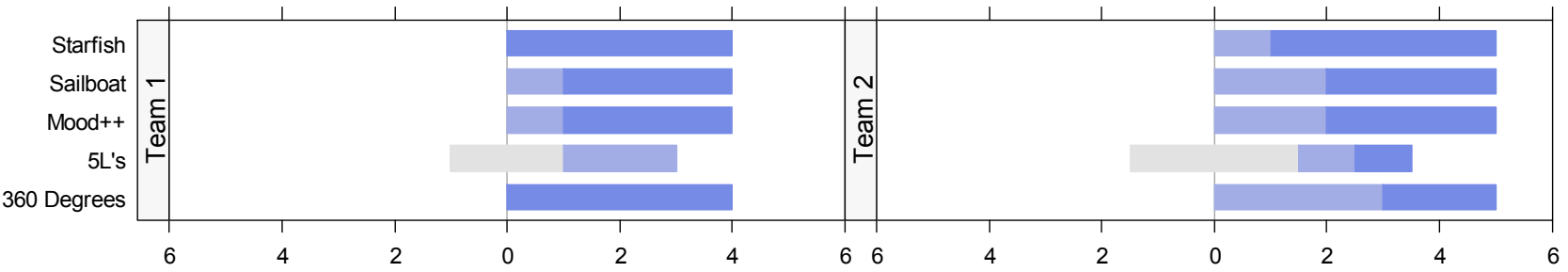

Strongly Agree $\square$ Somewhat Agree $\quad$ Neither Agree nor Disagree $\quad$ Somewhat Disagree $\quad$ Strongly Disagree

Figure 1. Aggregated results

\section{REFERENCES}

Baskerville, R., Myers, M.D.: Special issue on action research in information systems: making IS research relevant to practiceforeword. In: MIS Quart 28(3), pp. 329-335, 2004

Caroli, P., Caetano, T.: Fun Retrospectives - Activities and ideas for making agile retrospectives more engaging. Leanpub, 2016

Crawford, B., León de la Barra, C., Soto, R., Monfroy, E.: Agile software engineering as creative work. In: 5th International Workshop on Cooperative and Human Aspects of Software Engineering, Zürich, Switzerland, 2012

Ghanbari, H., Similä, J., Markkula, J.: Utilizing online serious games to facilitate distributed requirements elicitation. In: Journal of Systems and Softwar, vol. 109 (November 2015), pp. 32-49

Highsmith, J., Cockburn, A.: Agile Software Development: The Business of Innovation. In: IEEE Computer, vol. 34(9), pp. 120-122, Sep., 2001

Highsmith, J., Fowler, M.: The agile manifesto. In: Softw. Dev. Mag. 9, pp. 29-30, 2001

Hohmann, L.: Innovation Games: Creating Breakthrough Products Through Collaborative Play. Addison-Wesley Professional, 2006

Ilyés, E.: Create your own agile methodology for your research and development team. In: 2019 Federated Conference on Computer Science and Information Systems (FedCSIS'19), Leipzig, Germany, 2019

Jarzębowicz, A., Ślesiński, W.: Assessing Effectiveness of Recommendations to Requirements-Related Problems through Interviews with Experts. In: 2018 Federated Conference on Computer Science and Information Systems (FedCSIS'18), Poznan, Poland, 2018

Karpus, A., Raczyńska, M., Przybyłek, A.: Things You Might Not Know about the k-Nearest Neighbors Algorithm. In: 11th International Joint Conference on Knowledge Discovery, Knowledge Engineering and Knowledge Management, Vienna, 2019

Marciniak P., Jarzębowicz A.: An Industrial Survey on Business Analysis Problems and Solutions. In: Software Engineering: Challenges and Solutions, pp. 163-176, Advances in Intelligent Systems and Computing vol. 504, Springer International Publishing, (https://doi.org/10.1007/978-3-319-43606-7_12), 2016
Miler, J., Gaida, P.: On the Agile Mindset of an Effective Team - an Industrial Opinion Survey. In: 2019 Federated Conference on Computer Science and Information Systems (FedCSIS'19), Leipzig, Germany, 2019

Przybyłek, A.: A Business-Oriented Approach to Requirements Elicitation. In: 9th International Conference on Evaluation of Novel Approaches to Software Engineering, Lisbon, Portugal, 2014, doi: 10.5220/0004887701520163

Przybyłek, A.: An empirical study on the impact of AspectJ on software evolvability. In: Empirical Software Engineering, vol. 23(4), pp. 2018-2050, August 2018, https://doi.org/10.1007/s10664-017-95807, 2018

Przybyłek, A., Olszewski, M.: Adopting collaborative games into Open Kanban. In: 2016 Federated Conference on Computer Science and Information Systems (FedCSIS'16), Gdansk, Poland, 2016, doi: 10.15439/2016F509

Przybyłek, A., Kotecka, D.: Making agile retrospectives more awesome. In: 2017 Federated Conference on Computer Science and Information Systems (FedCSIS'17), Prague, Czech Republic, 2017, doi: $10.15439 / 2017 \mathrm{~F} 423$

Przybyłek, A., Kowalski, W.: Utilizing online collaborative games to facilitate Agile Software Development. In: 2018 Federated Conference on Computer Science and Informa-tion Systems (FedCSIS'18), Poznan, Poland, 2018, doi: 10.15439/2018F347

Przybyłek, A., Zakrzewski, M.: Adopting Collaborative Games into Agile Requirements Engineering. In: 13th International Conference on Evaluation of Novel Approaches to Software Engineering (ENASE'18), Funchal, Madeira, Portugal, 2018, doi: 10.5220/0006681900540064

Trujillo, M.M., Oktaba, H., González, J.C.: Improving Software Projects Inception Phase Using Games: ActiveAction Workshop. In: 9th International Conference on Evaluation of Novel Approaches to Software Engineering (ENASE'14), Lisbon, Portugal, 2014

Zakrzewski, M., Kotecka, D., Ng, Y.Y., Przybylek, A.: Adopting Collaborative Games into Agile Software Development. In: Damiani E., Spanoudakis G., Maciaszek L. (eds) Evaluation of Novel Approaches to Software Engineering. ENASE 2018. Communications in Computer and Information Science, vol 1023. Springer, Cham, 2019, doi: 10.1007/978-3-030-22559-9_6 